\title{
Synthesis and Optical Properties of Chitosan/polypyrrole Composite for Biological Applications
}

\author{
Nermin Gewili ${ }^{1 \mathbb{D}}$, Amr M. Abdelghany ${ }^{2 * \mathbb{E}}$, Mohamed Mekhaimer ${ }^{1 \mathbb{C}}$, Ahmed Oraby ${ }^{1 \mathbb{(}}$ \\ 1 Advanced Materials Research Laboratory, Physics Department, Faculty of Science, Mansoura University, 355165 , \\ Mansoura, Egypt \\ 2 Spectroscopy Department, Physics Division, National Research Centre, 33 El Behouth St., 12311, Dokki, Giza, Egypt \\ * Correspondence: a.m_abdelghany@yahoo.com;
}

Scopus Author ID 7003638023

Received: 29.01.2021; Revised: 20.03.2021; Accepted: 25.03.2021; Published: 8.05.2021

\begin{abstract}
Polypyrrole conducting polymers have become significant in different biomedical applications, but unfortunately, they are insoluble with poor mechanical properties. A natural soluble polymer (Chitosan) can be used to improve such properties. Chitosan/polypyrrole composites were synthesized by dispersing the different doped amounts of polypyrrole into the chitosan matrix. The physical properties of the synthesized composite films were investigated using different techniques. The results obtained from FTIR, XRD show the electrostatic interaction between chitosan and polypyrrole. UV/Vis analysis implies that the optical band gap of composite films decreases with increasing polypyrrole concentration, which can be assumed to increase the electrical conduction in the composite films.
\end{abstract}

Keywords: chitosan; polypyrrole; FTIR; UV/Vis; XRD.

(C) 2021 by the authors. This article is an open-access article distributed under the terms and conditions of the Creative Commons Attribution (CC BY) license (https://creativecommons.org/licenses/by/4.0/).

\section{Introduction}

Chitosan is a natural polymer derived from chitin's deacetylation, classified as linear multifunction polysaccharide composed glycoside repeating units: of deacetylated $\beta-(1,4)-D-$ glucosamine and acetylated unit $\mathrm{N}$-acetyl-D-glucosamine, with the chemical formula $\mathrm{C}_{56} \mathrm{H}_{103} \mathrm{~N}_{9} \mathrm{O}_{39}[1,2]$. These amine groups are active and can be chemically modified to improve their properties and enable different biological functions and the applications of modification reactions. Chitosan is biocompatible, biodegradable, and non-toxic, which can be used in different medical applications such as antimicrobial and wound healing biomaterials $[1,3]$. It can also be used in biosensor development due to its excellent ability of film-forming, mechanical strength, susceptibility to chemical modifications, and cost-effectiveness [4]. It also possesses poor electrical properties, which leads to poor response time, limiting its applications to a certain extent [2]. To improve its conductivity and bioactivity, dispersion of nanostructured conducting polymers has been considered. This dispersion promotes the transfer kinetics of electrons and enhances the stability and sensitivity of biosensors [3].

Polypyrrole (PPy) it was also termed at the time of its discovery in the 1960s as pyrrole black, is a synthetic polymer derived from chemical oxidative or chemical polymerization process of pyrrole, with chemical formula $\mathrm{H}\left(\mathrm{C}_{4} \mathrm{H}_{2} \mathrm{NH}\right)_{n} \mathrm{H}$ [5]. In normal condition, PPy is an insulator, but when oxidized, became a good conductive material. This conductivity ranges 
from 2 to $100 \mathrm{~S} / \mathrm{cm}$ depends on the type of reagent used in the oxidation [6]. Doped PPy is useful in biomedical applications because of its high electrical conductivity and ease of modification of the surface, such as drug delivery and regeneration of nerves, also used for coating of neural probes and in biosensors $[7,8]$. The morphological properties of oxidized PPy play an important role in achieving higher conductivity, higher melting point, and higher glass transition [9].

In the recent decade, the researcher received attention to exploring the potential of conducting polymers and electroactive polymers in different biomedical applications, such as biosensor; tissue engineering; drug delivery; moderator of nerve, skeletal muscles, cardiac, bone cells activities and coating electrodes used in sensing process of neural cells [10]. Electrically conducting polymers have certain mechanical properties, electrical conductivity and possess good biocompatibility has been a huge goal in biomedical applications to be useful in biomedical devices and implants [11].

Conducting polymers in recent years possess a great interest due to their easy synthesis, high electrical conductivity that can be modulated in magnitude over 15 orders, interesting electronics, good biocompatibility, and redox properties. However, PPy is poor in mechanical properties as it is rigid, brittle, non-biodegradable, and insoluble, which obstructed its use in medical applications [12, 13]. Many researchers seek to overcome these limitations and improve the properties and biocompatibility of PPy matrices by preparing composite or blend using a small amount of PPy (conducting nanoparticles) with non-conducting nanoparticles with suitable properties as chitosan and collagen. This obtained conductive composite can be adjusted to obtain the desired conductivity while maintaining the biocompatibility and flexibility of chitosan in biomedical applications such as neural tissue engineering [2, 13-16]. Chitosan/polypyrrole (CHI/PPy) composite can be used in the injured heart to improve the electrical conduction across the fibrotic scar, adjust ta impedance and potential of the fibrotic matrix of the myocardium, olfactory signals, and regulation of Schwann cells [17].

In the present study, CHI/PPy composite was synthesized by dissolving a different doped amount of PPy in chitosan matrix, chitosan also dissolved in 2\% acidic solution, which resulted in CHI/PPy composite films. The composite crystallinity, structural property, and optical bandgap were investigated using FTIR, UV/Vis, and XRD analysis.

\section{Materials and Methods}

\subsection{Materials.}

Chitosan of chemical formula $\left(\mathrm{C}_{6} \mathrm{H}_{11} \mathrm{NO}_{4}\right)_{\mathrm{n}}$, obtained from the deacetylation of chitin (deacetylation degree 85\%). It was supplied in a white tooff-white powder form from Alpha Aesar (USA). Polypyrrole (doped with proprietary organic acids, $5 \mathrm{wt} \%$ solutions in water) with chemical formula $\mathrm{H}\left(\mathrm{C}_{4} \mathrm{H}_{2} \mathrm{NH}\right)_{n} \mathrm{H}$, was supplied from Sigma-Aldrich.

\subsection{Sample preparation.}

Chitosan/polypyrrole bend was synthesized using the casting technique. $1 \mathrm{gm}$ of chitosan was dissolved in $2 \%$ aqueous acetic acid solution. Different concentrations of PPy were added to the pre-prepared chitosan solution. Sample nomination and composition are listed in table 1 below. Then the mixtures were then poured in plastic Petri-dishes and dried at $55^{\circ} \mathrm{C}$ for $48 \mathrm{~h}$ to obtain composite thin films. 
Table 1. Sample nomination and composition.

\begin{tabular}{l|c|c|c|c|c|c} 
Sample & CHI-PPy0 & CHI-PPy1 & CHI-PPy2 & CHI-PPy3 & CHI-PPy4 & CHI-PPy5 \\
\hline PPy conc. & 0.00 & 0.03 & 0.06 & 0.0125 & 0.025 & 0.3
\end{tabular}

\subsection{Physical measurements.}

Furrier transformation infrared spectra (Nicolet $i S 10)$ of the samples were recorded in transition mode, with a frequency range of $4000-400 \mathrm{~cm}^{-1}$. X-ray diffraction (XRD) analysis using (PAN analytical X' Pert PRO XRD system) with a wavelength $\lambda=1.540 \mathrm{~A}^{\circ}$, occupied with $\mathrm{Cu} \mathrm{K} \alpha$ radiation with an operating voltage of $30 \mathrm{kV}$. UV/Vis spectrometer (T80+) in a wavelength range $200-1100 \mathrm{~nm}$.

\section{Results and Discussion}

\subsection{Fourier transform infrared analysis.}

FTIR investigation was carried out to confirm the existing functional group in the Chitosan/Polypyrrole (CHI/PPy) blends. Figure 1 shows the absorption data obtained from FTIR for pure chitosan, PPy, and their blends spectra. The vibrations of chitosan were observed at an absorption band $3462 \mathrm{~cm}^{-1}$ was assigned to the presence of $\mathrm{N}-\mathrm{H}$ stretching vibration overlapped in the same region by $\mathrm{O}-\mathrm{H}$ stretching [18]. A small peak at $2872 \mathrm{~cm}^{-1}$ corresponds to $\mathrm{C}-\mathrm{H}$ stretching vibration, while $1654 \mathrm{~cm}^{-1}$ corresponds to the $\mathrm{C}=\mathrm{O}$ stretching vibration of NHCO- [3, 18-22]. The strong band at $1578 \mathrm{~cm}^{-1}$ and $1417 \mathrm{~cm}^{-1}$ can be attributed to $\mathrm{N}-\mathrm{H}$ and $\mathrm{C}-\mathrm{H}_{2}$ bending vibrations, respectively [22]. Peaks at $1150 \mathrm{~cm}^{-1}$ and $1099 \mathrm{~cm}^{-1}$ correspond to $\mathrm{C}-\mathrm{O}$, and $\mathrm{C}-\mathrm{O}-\mathrm{C}$ linkage of glucosamine rings. Compared pure chitosan and chitosan doped with different concentration of $\mathrm{PPy}$, the shifting of $\mathrm{C}=\mathrm{O}$ bond stretching vibration $\left(1654 \mathrm{~cm}^{-1}\right)$ to the right (lower wavenumber) indicate the formation of the hydrogen bond between the secondary amide group of chitosan and $-\mathrm{NH}$ group of PPy [3]. PPy has a characteristics band at $1573 \mathrm{~cm}-1$ and $1403 \mathrm{~cm}-1$ due to $\mathrm{C}=\mathrm{C}$ and $\mathrm{C}-\mathrm{N}$ stretching vibrations, respectively [3, 23]. And a band at $676 \mathrm{~cm}^{-1}$ describes $\mathrm{C}-\mathrm{H}$ wagging vibration of the pyrrole ring $[19,20]$. It was observed a shifting in the broadband $3462 \mathrm{~cm}-1$ to the right, which suggested an electrostatic interaction between - $\mathrm{NH}$ group of PPy and - $\mathrm{OH}$ functional group of chitosan [3].

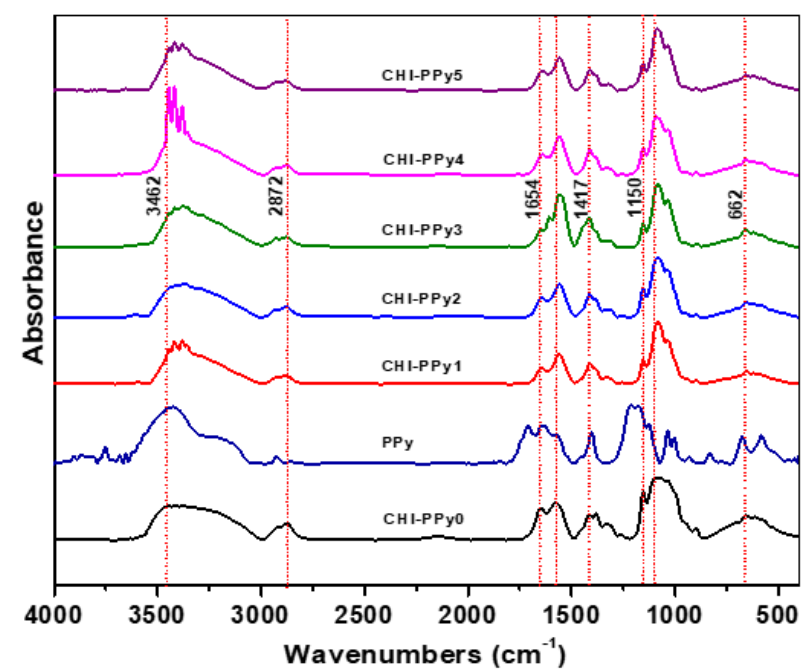

Figure 1. FTIR absorption spectra of pure chitosan, pure polypyrrole and CHI/PPy blend containing different concentrations of PPy. 


\subsection{X-ray diffraction analysis (XRD).}

The obtained XRD data shown in figure 2, for pure chitosan (Co) appeared characteristic peaks at $2 \theta=20.7^{\circ}$ and a small peak at $2 \theta=14.8^{\circ}$, which indicated the semicrystalline property of chitosan $[18,22]$. For CHI/PPy blend showed broadband in the $2 \theta$ range of $15^{\circ}-33^{\circ}$, this range increase with increasing concentration, but the peak intensity decreases this exhibit the amorphous structure of the CHI/PPy composites [3].

The small peak $\left(14.8^{\circ}\right)$ of chitosan disappeared, demonstrating that chitosan and PPy components inside the composite have interacted with each other, resulting from the hydrogen bonds between chitosan and PPy [22].

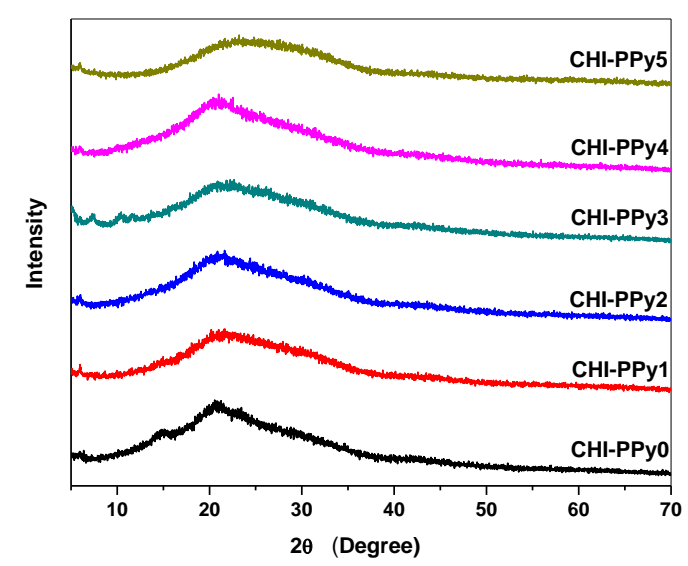

Figure 2. X-ray diffraction of CHI/PPy blends with different PPy contents.

\subsection{UV/Vis optical absorption.}

Figure 3 shows optical absorption spectra of chitosan, polypyrrole, and their blends $\mathrm{CHI} / \mathrm{PPy}$ with different concentrations of doped PPy. The obtained spectra of pure CHI exhibit no significant peaks in this absorption region. Pure PPy spectra show two bands at $238 \mathrm{~nm}$ and $392 \mathrm{~nm}$ corresponds to molecular conjugation and bipolaron state of PPy. Simultaneously, the spectra of CHI/PPy blends show a very small peak near $220 \mathrm{~nm}$, which indicates weak electrostatic interaction between chitosan and polypyrrole, as recognized from FTIR characterization [13]. The obtained peaks of composites indicate the electron transition from a valance band to the antibonding polaron state. The wavelength of these valance band and antibonding polaron transition shows a red-shift with increasing PPy concentration. This means that the optical energy gap decreases, leading to an increase in the composite [24].

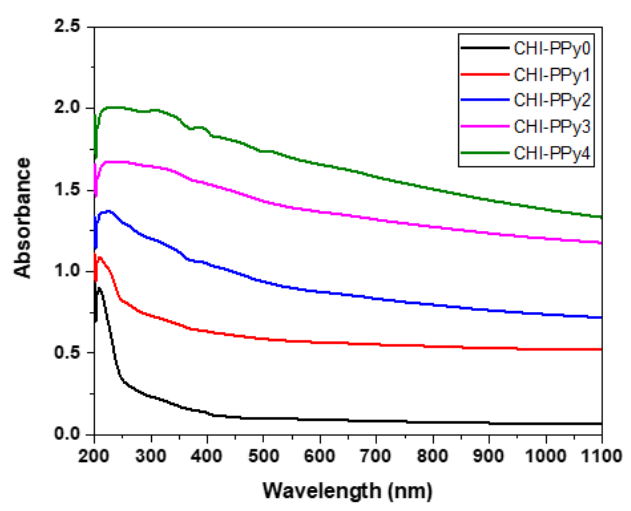

Figure 3. UV/Vis. Optical absorption spectra of CHI/PPy blends with different PPy contents. 


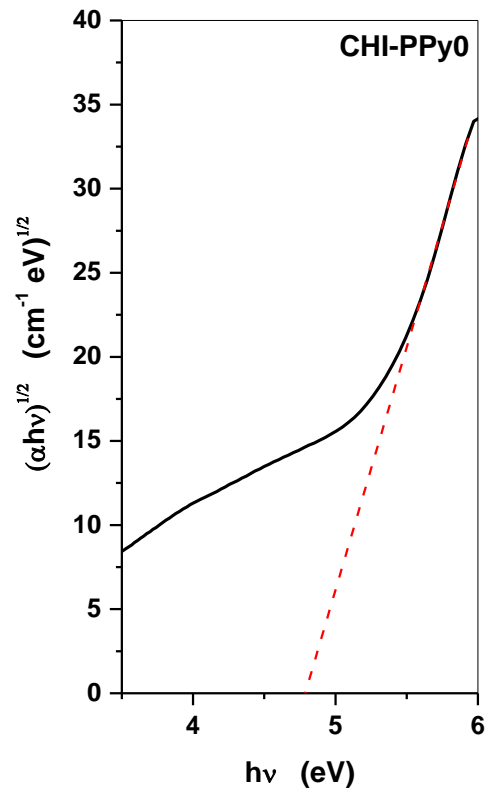

(a)

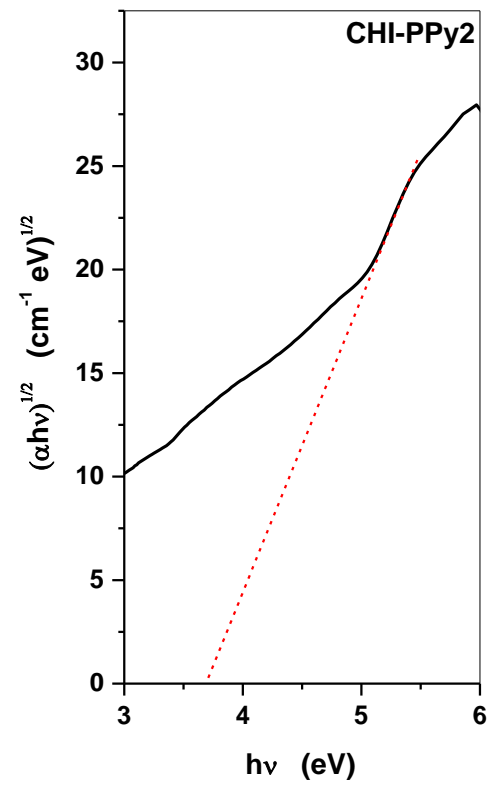

(c)

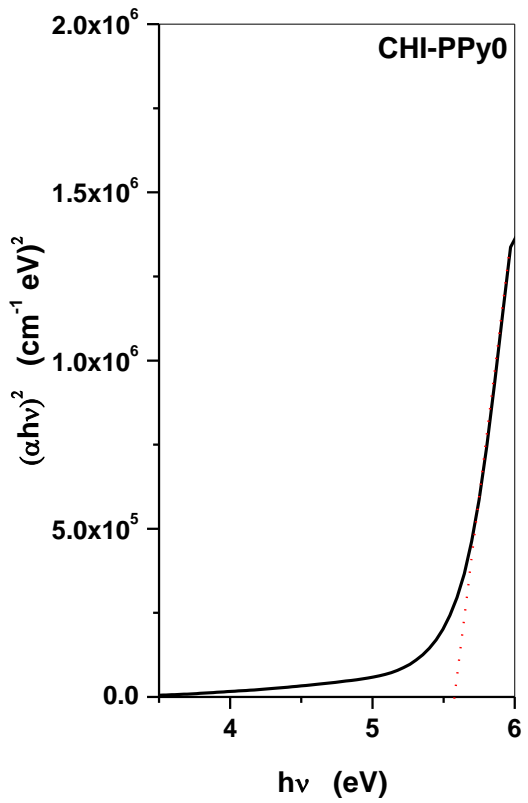

(b)

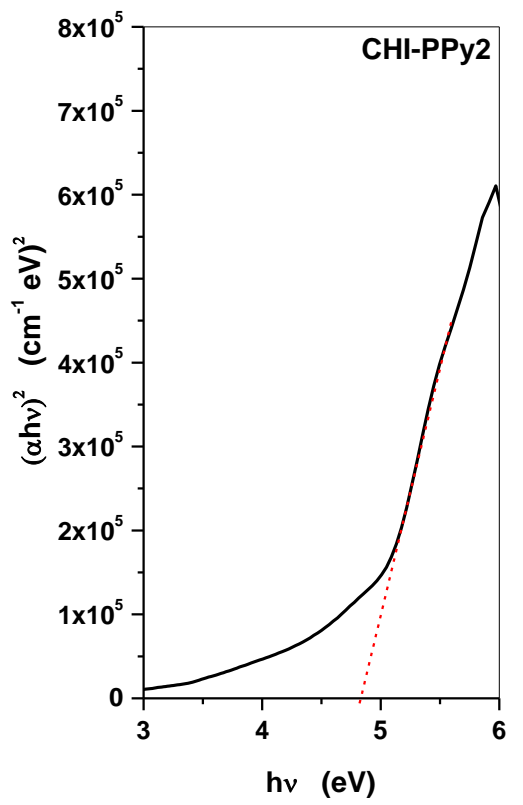

(d)

Figure 4. Tauc's plot of some selected samples (a, b) CHI-PPy0, and (c, d) CHI-PPy2.

The optical energy gap of CHI/PPy composite can be calculated from Tauc's formula:

$$
\alpha h v=A\left(h v-E_{g}\right)^{n}
$$

Where $\alpha$ is the absorption coefficient, $h$ is Planck's constant, $v$ is the frequency, $A$ is the proportionality constant, $E_{g}$ is the energy gap, and $n=2$ or $\frac{1}{2}$ which means direct or indirect transition. Using Tauc's plot shown in figure 4 represented by a relation between $\left[(\alpha h v)^{\frac{1}{2}}\right.$ and $(\alpha h v)^{2}$ ] Vs photon energy $h v$. We can determine the energy gap $E_{g}$ at the X-axis intercept in case of both direct and indirect transition [25]. Optical energy gaps are estimated using fundamental absorption edge, and Tauc's equation is listed in table 2 and plotted in figure 5. Also, the results were confirmed using HUMO-LUMO calculations shown in figure 6. 

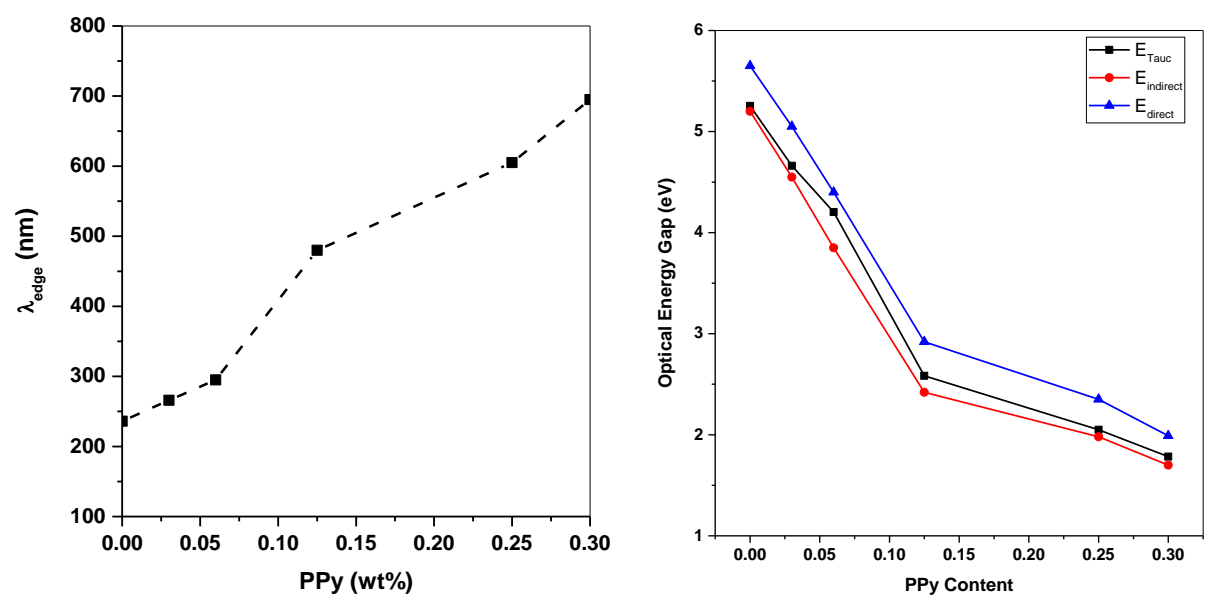

Figure 5. Relation between PPy content and absorption edge (a), and optical energy gap (b).

Table 2. Estimated and calculated optical energy gap for the studied samples

\begin{tabular}{|c|c|c|c|c|c|}
\hline \multirow[t]{2}{*}{ Sample } & \multirow[t]{2}{*}{ PPy Content } & $\lambda_{\text {Edge }}$ & $\mathbf{E}_{\text {Direct }}$ & EIndirect & $\mathbf{E}_{\text {Tauc }}$ \\
\hline & & $(\mathbf{n m})$ & \multicolumn{3}{|c|}{$(\mathrm{eV})$} \\
\hline CHI-PPy0 & 0.000 & 236 & 5.65 & 5.20 & 5.25 \\
\hline CHI-PPy1 & 0.030 & 266 & 5.05 & 4.55 & 4.66 \\
\hline CHI-PPy2 & 0.060 & 295 & 4.40 & 3.85 & 4.20 \\
\hline CHI-PPy3 & 0.125 & 480 & 2.92 & 2.42 & 2.58 \\
\hline CHI-PPy4 & 0.250 & 605 & 2.35 & 1.98 & 2.05 \\
\hline CHI-PPy5 & 0.300 & 695 & 1.99 & 1.70 & 1.78 \\
\hline
\end{tabular}

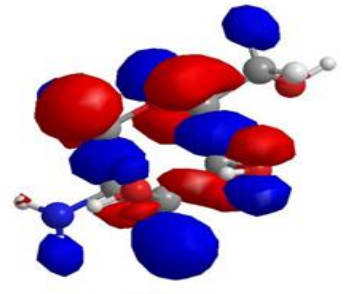

(A)

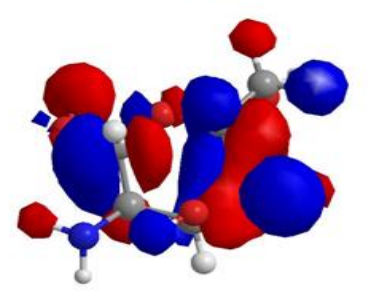

(B)

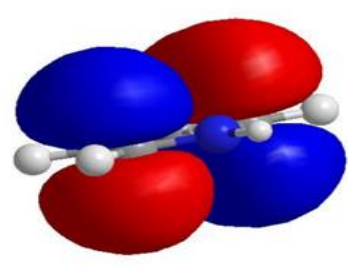

(c)

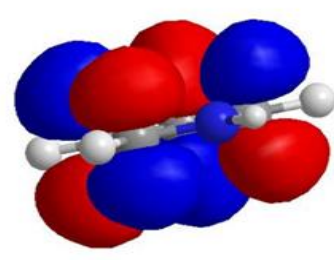

(D)

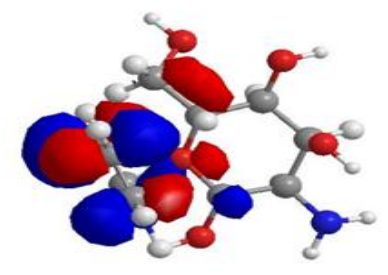

(E)

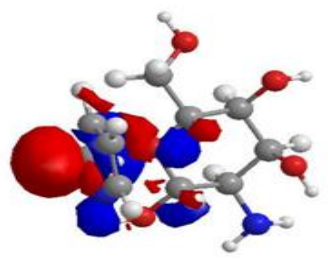

(F)

Figure 6. Chitosan, Polypyrrole and CHI/PPy composite 3D structure: (A) HOMO of chitosan (-10.976 eV), (B) LUMO of chitosan (21.216 eV), (C) HOMO of PPy (-13.123 eV), (D) LUMO of PPy (7.658 eV), (D) HOMO of CHI/PPy (6.143 eV) and (F) LUMO of CHI/PPy (7.147 eV).

\section{Conclusions}

Conductive polymers such as polypyrrole have hindered biomedical applications as they are insoluble and have poor mechanical properties. Chitosan can be used to improve these properties. Chitosan/polypyrrole composites were synthesized in different polypyrrole doped concentrations. The obtained analyzed data showed the interaction between chitosan and polypyrrole. Increasing polypyrrole concentrations decreases the optical band gap, which leads to an increase in its conductivity. That means composite conductivity can be adjusted to a certain amount to be used in different biological applications such as nerve impulse moderation, cardio impulse generation, myocardial infraction, neural tissue engineering, and biosensors. 


\section{Funding}

This research received no external funding.

\section{Acknowledgments}

This research has no acknowledgment.

\section{Conflicts of Interest}

The authors declare no conflict of interest.

\section{References}

1. Santos, V.P.; Marques, N.S.S.; Maia, P.C.S.V.; Lima, M.A.; Franco, L.D.; Campos-Takaki, G.M. Seafood Waste as Attractive Source of Chitin and Chitosan Production and Their Applications. International Journal of Molecular Sciences 2020, 21, https://doi.org/10.3390/ijms21124290.

2. Antony, N.; Mohanty, S.; Nayak, S.K. Electrochemical inspection of polypyrrole/chitosan/zinc oxide hybrid composites. Journal of Applied Polymer Science 2020, 137, https://doi.org/10.1002/app.49561.

3. Jiang, Y.; Wu, J. Recent development in chitosan nanocomposites for surface-based biosensor applications. Electrophoresis 2019, 40, 2084-2097, https://doi.org/10.1002/elps.201900066.

4. Roekmono; Hadi, H.; Nur Imtihani, H.; Wahyuono, R. Paper-Based Biosensor for Glucose and Paracetamol Sensing using Chitosan/ Graphene Oxide Modified Electrode. International Journal of Drug Delivery Technology 2020, 10, 295-300, https://doi.org/10.25258/ijddt.10.2.18.

5. El-Nahrawy, A.M.; Abou Hammad, A.B.; Khattab, T.A.; Haroun, A.; Kamel, S. Development of electrically conductive nanocomposites from cellulose nanowhiskers, polypyrrole and silver nanoparticles assisted with Nickel(III) oxide nanoparticles. Reactive and Functional Polymers 2020, 149, https://doi.org/10.1016/j.reactfunctpolym.2020.104533.

6. Li, X.; Chen, X.; Jin, Z.; Li, P.; Xiao, D. Recent progress in conductive polymers for advanced fiber-shaped electrochemical energy storage devices. Materials Chemistry Frontiers 2021, https://doi.org/10.1039/D0QM00745E.

7. Salehi, M.H.; Golbaten-Mofrad, H.; Jafari, S.H.; Goodarzi, V.; Entezari, M.; Hashemi, M.; Zamanlui, S. Electrically conductive biocompatible composite aerogel based on nanofibrillated template of bacterial cellulose/polyaniline/nano-clay. International Journal of Biological Macromolecules 2021, 173, 467-480, https://doi.org/10.1016/j.ijbiomac.2021.01.121.

8. Nöth, M.; Zou, Z.; El-Awaad, I.; Celia de Lencastre Novaes, L.; Dilarri, G.; Davari, M.D.; Ferreira, H.; Jakob, F.; Schwaneberg, U. A peptide-based coating toolbox to enable click chemistry on polymers, metals, and silicon through sortagging. Biotechnology and Bioengineering 2021, https://doi.org/10.1002/bit.27666.

9. Yussuf, A.; Al-Saleh, M.; Al-Enezi, S.; Abraham, G. Synthesis and Characterization of Conductive Polypyrrole: The Influence of the Oxidants and Monomer on the Electrical, Thermal, and Morphological Properties. International Journal of Polymer Science 2018, 2018, https://doi.org/10.1155/2018/4191747.

10. Idumah, C.I. Recent advancements in conducting polymer bionanocomposites and hydrogels for biomedical applications. International Journal of Polymeric Materials and Polymeric Biomaterials 2020, 1-18, https://doi.org/10.1080/00914037.2020.1857384.

11. Kiran, I.; Shad, N.A.; Sajid, M.M.; Jamil, Y.; Javed, Y.; Hussain, M.I.; Akhtar, K. Graphene Functionalized PLA Nanocomposites and Their Biomedical Applications. In: Graphene Based Biopolymer Nanocomposites. Sharma, B.; Jain, P. Eds. Springer Singapore: Singapore, 2021; 83-105, https://doi.org/10.1007/978-981-15-9180-8_5.

12. Chavoshizadeh, S.; Pirsa, S.; Mohtarami, F. Conducting/smart color film based on wheat gluten/chlorophyll/polypyrrole nanocomposite. Food Packaging and Shelf Life 2020, 24, https://doi.org/10.1016/j.fpsl.2020.100501.

13. Alipour, A.; Mansour Lakouraj, M.; Tashakkorian, H. Study of the effect of band gap and photoluminescence on biological properties of polyaniline/CdS QD nanocomposites based on natural polymer. Scientific Reports 2021, 11, 1-15, https://doi.org/10.1038/s41598-020-80038-1.

14. Sun, Y.; Liu, X.; George, M.N.; Park, S.; Gaihre, B.; Terzic, A.; Lu, L. Enhanced nerve cell proliferation and differentiation on electrically conductive scaffolds embedded with graphene and carbon nanotubes. Journal of Biomedical Materials Research Part A 2021, 109, 193-206, https://doi.org/10.1002/jbm.a.37016.

15. da Silva Alves, D.C.; Healy, B.; Pinto, L.A.d.A.; Cadaval, T.R.S.A.; Breslin, C.B. Recent Developments in Chitosan-Based Adsorbents for the Removal of Pollutants from Aqueous Environments. Molecules 2021, 26, https://doi.org/10.3390/molecules26030594. 
16. Abedi, A.; Bakhshandeh, B.; Babaie, A.; Mohammadnejad, J.; Vahdat, S.; Mombeiny, R.; Moosavi, S.R.; Amini, J.; Tayebi, L. Concurrent application of conductive biopolymeric chitosan/ polyvinyl alcohol/ MWCNTs nanofibers, intracellular signaling manipulating molecules and electrical stimulation for more effective cardiac tissue engineering. Materials Chemistry and Physics 2021, 258, https://doi.org/10.1016/j.matchemphys.2020.123842.

17. Cui, Z.; Ni, N.C.; Wu, J.; Du, G.-Q.; He, S.; Yau, T.M.; Weisel, R.D.; Sung, H.-W.; Li, R.-K. Polypyrrolechitosan conductive biomaterial synchronizes cardiomyocyte contraction and improves myocardial electrical impulse propagation. Theranostics 2018, 8, 2752-2764, https://doi.org/10.7150/thno.22599.

18. Saqib, M.; Ali Khan, S.; Mutee Ur Rehman, H.M.; Yang, Y.; Kim, S.; Rehman, M.M.; Young Kim, W. High-Performance Humidity Sensor Based on the Graphene Flower/Zinc Oxide Composite. Nanomaterials 2021, 11, https://doi.org/10.3390/nano11010242.

19. Momina; Ahmad, K. Study of different polymer nanocomposites and their pollutant removal efficiency: Review. Polymer 2021, 217, https://doi.org/10.1016/j.polymer.2021.123453.

20. Nellaiappan, S.; Devi, K.S.; Selvaraj, S.; Krishnan, U.M.; Yakhmi, J.V. Chemical, Gas and Optical Sensors Based on Conducting Polymers. In: Advances in Hybrid Conducting Polymer Technology. Springer, Cham. 2021; pp. 159-200, https://doi.org/10.1007/978-3-030-62090-5_8.

21. Xu, J.; Fu, C.-Y.; Tsai, Y.-L.; Wong, C.-W.; Hsu, S.-H. Thermoresponsive and Conductive ChitosanPolyurethane Biocompatible Thin Films with Potential Coating Application. Polymers 2021, 13, https://doi.org/10.3390/polym13030326.

22. Alagarsamy, K.N.; Mathan, S.; Yan, W.; Rafieerad, A.; Sekaran, S.; Manego, H.; Dhingra, S. Carbon nanomaterials for cardiovascular theranostics: Promises and challenges. Bioactive Materials 2021, 6, 22612280, https://doi.org/10.1016/j.bioactmat.2020.12.030.

23. Brza, M.A.; Aziz, S.B.; Anuar, H.; Ali, F.; Dannoun, E.M.A.; Mohammed, S.J.; Abdulwahid, R.T.; AlZangana, S. Tea from the drinking to the synthesis of metal complexes and fabrication of PVA based polymer composites with controlled optical band gap. Scientific Reports 2020, 10, 1-17, https://doi.org/10.1038/s41598-020-75138-x.

24. Capper, P.; Willoughby, A.; Kasap, S. Optical Properties of Materials and Their Applications. John Wiley \& Sons. 2020.

25. Ahmed, M.K.; Menazea, A.A.; Abdelghany, A.M. Blend biopolymeric nanofibrous scaffolds of cellulose acetate/ $\varepsilon$-polycaprolactone containing metallic nanoparticles prepared by laser ablation for wound disinfection applications. International Journal of Biological Macromolecules 2020, 155, 636-644, https://doi.org/10.1016/j.ijbiomac.2020.03.257. 